Article

\title{
Study on the Hybrid Cooling of the Flame Tube in a Small Triple-Swirler Combustor
}

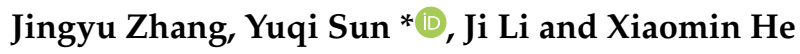 \\ College of Energy and Power Engineering, Nanjing University of Aeronautics and Astronautics, Nanjing 210016, \\ China; zjyhxm@nuaa.edu.cn (J.Z.); wxy_lila@nuaa.edu.cn (J.L.); hxm@nuaa.edu.cn (X.H.) \\ * Correspondence: sunyuqi@nuaa.edu.cn
}

Received: 17 September 2020; Accepted: 21 October 2020; Published: 23 October 2020

check for updates

\begin{abstract}
An experimental and numerical investigation is conducted to study the influence of different cooling schemes on the wall temperature of the flame tube in a small triple-swirler combustor in this paper. Two different cooling structures are adopted: the impingement-film and inclined multi-hole cooling structure (Scheme B, C), and the inclined multi-hole control group (Scheme A). The impact of parameters including inlet temperature (373-423 K), inlet Mach number (Ma) (0.12-0.18), and fuel-air ratio (FAR) (0.02-0.03) are discussed. The results show that the wall temperature of the flame tube rises with the increase in inlet temperature; as the inlet Mach number increases, the wall temperature (Scheme B, C) of the primary zone goes up and is distributed more uniformly; as FAR rises, the wall temperature in Scheme $\mathrm{C}$ is nearly unchanged, while it is increased in Scheme $\mathrm{A}$ and $\mathrm{B}$. For the range of parameters considered in this study, the lowest wall temperature and the best cooling effect are observed in Scheme $\mathrm{C}$. The experiment conducted on the impingement-film and inclined multi-hole structure shows a better cooling effect than that conducted on the traditional inclined multi-hole structure. Compared with the row number of multi-inclined holes, the diameter of jet hole has a more significant influence on the cooling effect.
\end{abstract}

Keywords: inclined multi-hole; impingement-film cooling; triple-swirler combustor; experimental investigation; wall temperature

\section{Introduction}

In order to improve the engine thermodynamic performance and reduce pollutant emissions, multi-swirlers have recently engaged in modern advanced combustors [1-4]. A multi-swirler consists of several swirlers aligned in the same and opposite directions. The triple-swirler, one kind of multi-swirler, is very complicated as it features three swirling flow passages. Reduction in emissions and improvement in combustion performance can be achieved by distributing fuel properly in the triple-swirler in the combustion process. A typical flow field structure of a triple-swirler combustor is shown in Figure 1 [5]. The TAPS (Twin Annular Premixing Swirler) and the combustor employed in the paper are both triple-swirler combustors, and there are certain similarities in the flow characteristics. The primary zone of the combustion chamber is divided into two parts: the main recirculation zone, and the pilot recirculation zone. Generally, the flame stability and combustion performance can be guaranteed by the pilot recirculation zone under small operating conditions, while the main recirculation zone guarantees combustion performance under high-power conditions [6]. Low emission of NOx (nitrogen oxides) is a characteristic of the triple-swirler combustor, which requires more air in the combustion process [7]. Therefore, it is essential to improve cooling designs to keep the temperature level and thermal gradients in the flame tube within acceptable limits using minimum cooling air. 


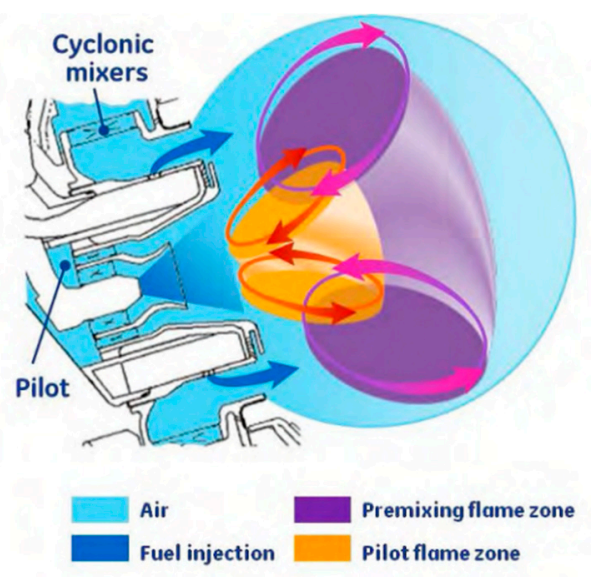

Figure 1. Typical flow field structure of a triple-swirler combustor.

The effusion cooling is a high-efficiency cooling technology due to the enhancement of convection heat transfer in the hole, which is shown in Figure 2 [8]. The air coolant engaged in the combustion operated on the inclined multi-hole cooling structure can be reduced by $40 \%$ compared with that operated on the slot film cooling structure [9]. Gustafsson and Johansson [10] measured the temperature distribution of the surface of the inclined multi-hole film with an infrared thermal imager. The cooling effect can be effectively improved by reducing the spacing of holes and reducing the injection angle of holes to keep the film more attached to the wall. The experimental studies by Andrews et al. [11-15] provide more detailed information into the inclined multi-hole cooling. They found that reducing the hole diameter and increasing the number of holes are beneficial to the enhancement of the cooling effect, the ratio of the spanwise spacing to the diameter of holes should be reduced in order to improve the cooling effect, and that the cooling effect of staggered holes is obviously better than that of in-line holes. It is beneficial to improve the cooling effect ensuring that the spanwise spacing is smaller than the streamwise spacing. Andrews et al. [11-15] also compared a high-temperature experiment $\left(\mathrm{T}_{\mathrm{h}}=2100 \mathrm{~K}, \mathrm{~T}_{\mathrm{c}}=700 \mathrm{~K}\right)$ and a relatively low-temperature experiment $\left(\mathrm{T}_{\mathrm{h}}=750 \mathrm{~K}, \mathrm{~T}_{\mathrm{c}}=300 \mathrm{~K}\right)$. It is found that the overall cooling effectiveness under the high-temperature experiment is lower due to the high temperature radiation.

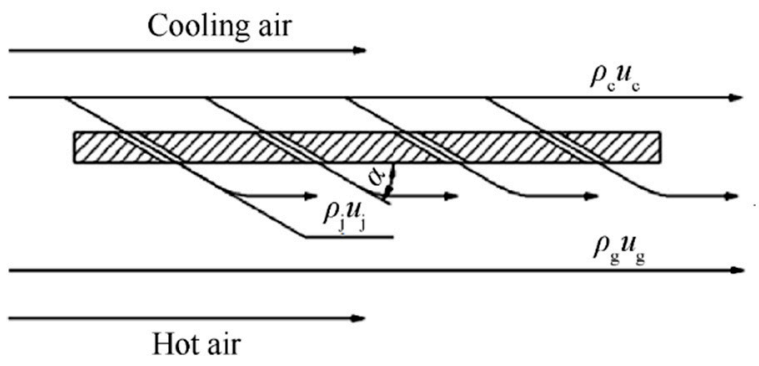

Figure 2. Inclined multi-hole film cooling structure.

As shown in Figure 3 [16], the impingement-film cooling structure with an inducting slab is also an effective cooling technique. Coolant air from jet holes impinges against the inducting slab, merging in the inducting cavity, forming a uniform film at the exit due to the pre-mix of jets in the slots. The f-type layout has been used in the combustor liner of the AL-31F engine (see Figure 4), which shows an excellent cooling performance. Wei et al. [17] presented that the inducting slab with a triangular cross-section slab can reduce the formation of entraining vortices. The inducting slab with a triangular cross-section slab shows $85.87 \%$ increased higher cooling efficiency than the one with rectangular cross-section. Wei and Zhang et al. [18] compared the adiabatic cooling effectiveness for t-type and f-type impingement-film cooling experimentally. The results show that the f-type 
layout has a better cooling performance than the t-type layout. The experiments were carried out on impingement-film hybrid cooling by Zhang et al. [16] The impingement-film structure shows a positive overall cooling effectiveness when $\mathrm{Ln} / \mathrm{d}$ is eight and $\mathrm{Zn} / \mathrm{d}$ is 0.5 (see Figure 3). Jambunathan et al. [19] analyzed the influence factor for a single circular jet impingement experimentally. The result indicates that the heat transfer coefficient is affected by jet radial length, nozzle-to-plate spacing, and Reynolds number. An overview is given on the use of several complex multi-swirler devices in gas turbine combustion by Mongia et al. [20] They investigated the impingement-film cooling scheme in an annular combustor liner, which is shown in Figure 5 (numbers in the picture represent the percentage of coolant). The research indicates that a higher fraction of the cooling air and a higher convection velocity creates an additional shear-layer to complete combustion without creating hot-streak on the liner walls.

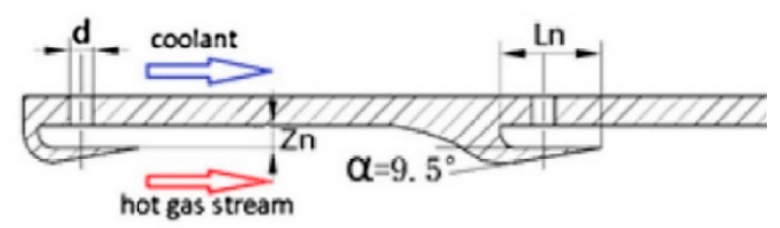

Figure 3. Impingement-film cooling structure with inducting slab.

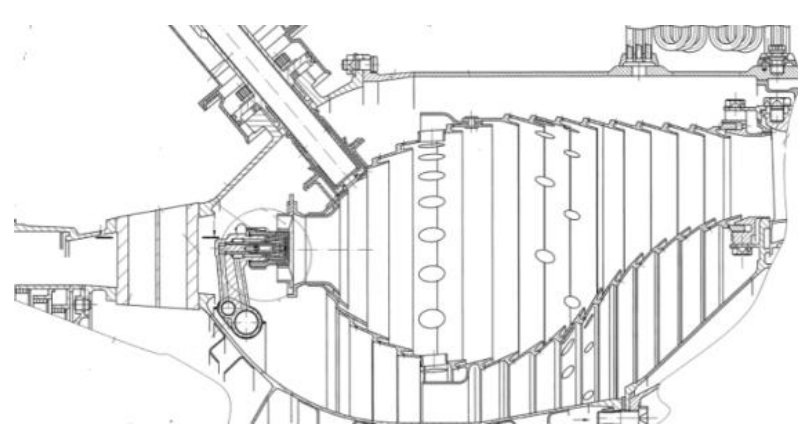

Figure 4. Combustor of AL-31F.

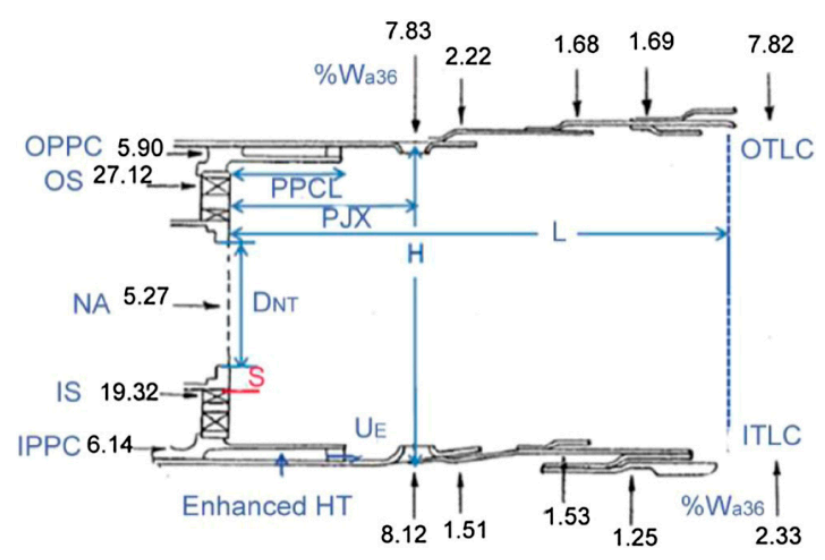

Figure 5. Impingement-film structure on combustor liner (from Mongia et al.).

The inclined multi-hole cooling structure has the advantages of high cooling efficiency and low consumption of cooling air. However, the overall cooling effectiveness of the first four rows is relatively low because of the existence of the pileup effect of the film. The flame tube of the small triple-swirler combustor has the characteristics of small structure size and short continuous surface. Hence, the advantages of the multi-inclined-hole cooling structure are not obvious. Sufficient Reynolds number must be guaranteed when the impingement-film cooling technology is introduced. However, Reynolds number is determined by the actual cooling air, which is limited by the pressure difference 
between the inside and outside of the flame tube. Therefore, to combine the advantages of both cooling structures, a hybrid cooling structure with the impingement-film and the multi-inclined holes is proposed, which is the novelty of this work.

The paper is organized as follows: Section 2 presents the model of the small triple-swirler combustor and the structural parameters of the three cooling schemes. Section 3 shows the research methods including the experiment methods and the numerical simulation methods. Section 4 presents the analysis of the experimental results and the comparison of the three schemes. Section 5 presents the conclusions and makes a comparison with other previous works.

\section{Flame Tube Model and Cooling Structure Layout}

The combustion chamber model in this study is shown in Figure 6. The triple-swirler is shown in Figure 7, which consists of an inner swirler, an intermediate swirler (radial), an outer swirler (radial), a primary venturi, a secondary venturi, and a flare.

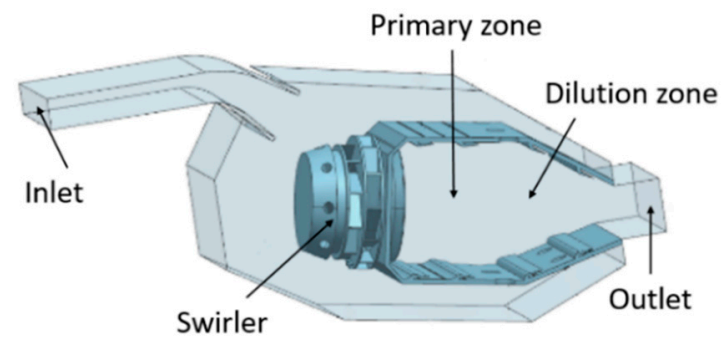

Figure 6. Geometric model of combustor.

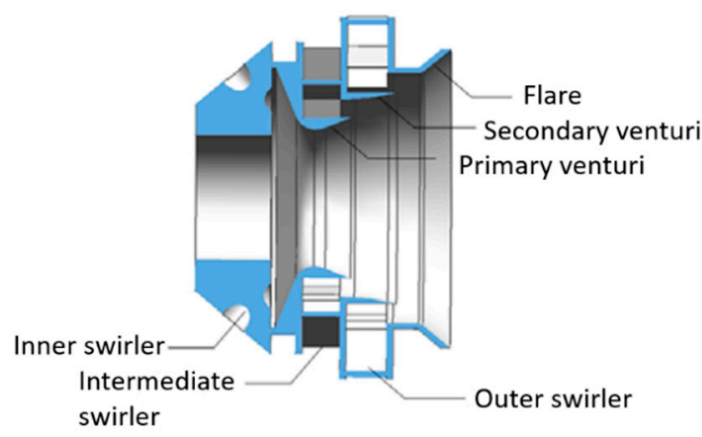

Figure 7. Triple-swirler assembly.

In order to protect the flame tube, two cooling structures are adopted. The inclined multi-hole cooling structure is employed in Scheme A (see Figure 8). The impingement-film and inclined multi-hole cooling structure is used in Scheme B (Figure 9) and Scheme C (Figure 10). Scheme A, and B share the same cooling structure of the flame tube head as Scheme C. Furthermore, $30^{\circ}$ multi-inclined holes and straight holes are adopted and the diameter of all the holes is $0.8 \mathrm{~mm}$, as shown in Figure 11 .

The inclined multi-hole structure in Scheme A is shown in Figure 8. The cooling structure of the primary zone and the dilution zone is designed with the same geometric parameters. Based on the research of Andrews et al. [11-15], the corresponding geometric structure is selected. The specific geometric parameters are shown in Table 1.

The impingement-film and inclined multi-hole cooling structure in Scheme B is shown in Figure 9. Considering the effective length of the impingement-film and the limitation of the geometric dimensions of the flame tube, two rows of jet holes are arranged on the wall of the primary zone and the dilution zone, and several rows of multi-inclined holes are arranged upstream of the inducting slab, respectively. According to the results of the references [16-18], an inducting slab with triangular cross-section is 
adopted, and the leading edge of the inducting slab is streamlined. The specific geometric parameters are shown in Table 1.

The impingement-film and inclined multi-hole cooling structure in Scheme $C$ is shown in Figure 10. The diameter of jet holes in Scheme B is adjusted from 1.0 to $1.6 \mathrm{~mm}$, which is different from Scheme C. In order to ensure the same coolant mass flow rate per unit area, the number of rows of multi-inclined holes is decreased appropriately and one row of multi-inclined holes is removed upstream of the third and the fourth inducting slab, respectively, as shown in Figure 10.

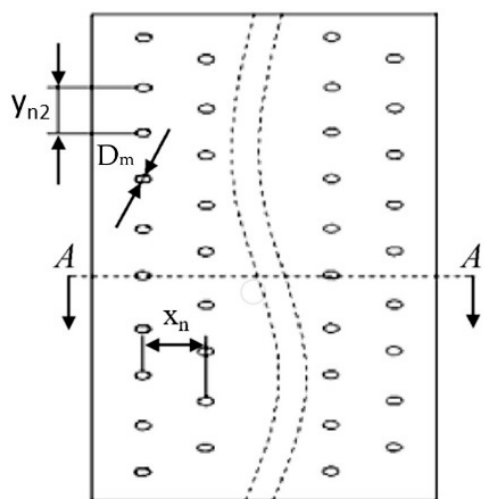

(a)

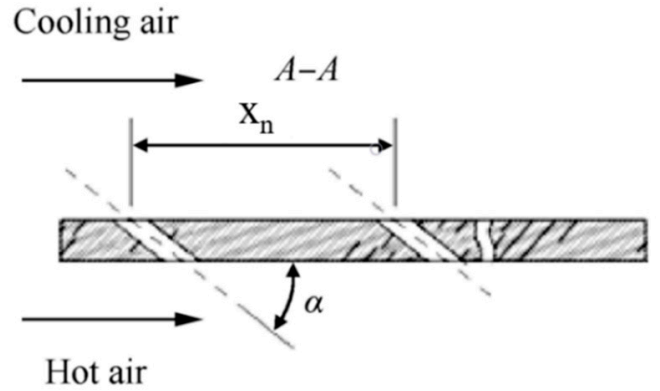

(b)

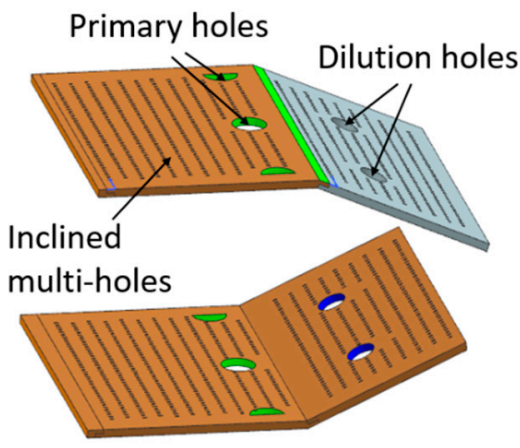

(c)

Figure 8. Scheme A cooling structure layout: (a) layout of film cooling holes; (b) section A-A; (c) cooling scheme of flame tube wall.

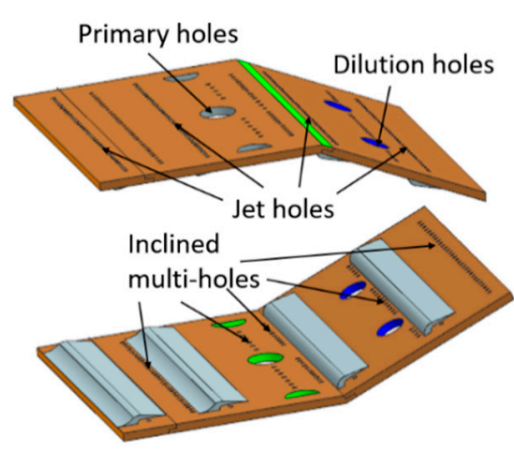

(a)

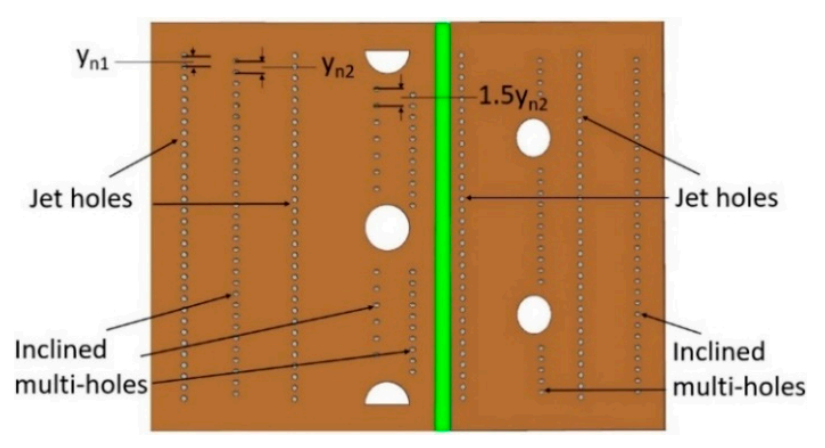

(b)

Figure 9. Scheme B cooling structure layout: (a) cooling scheme of flame tube wall; (b) layout of film cooling holes. 


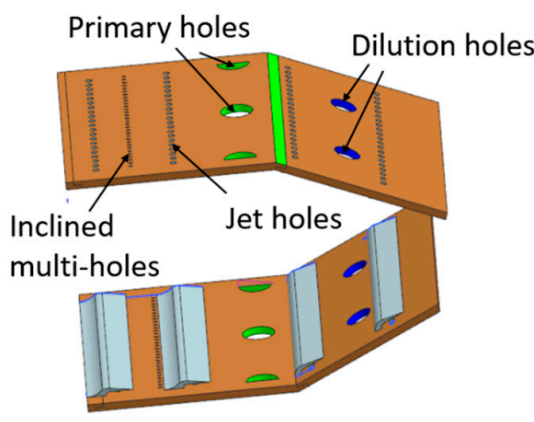

(a)

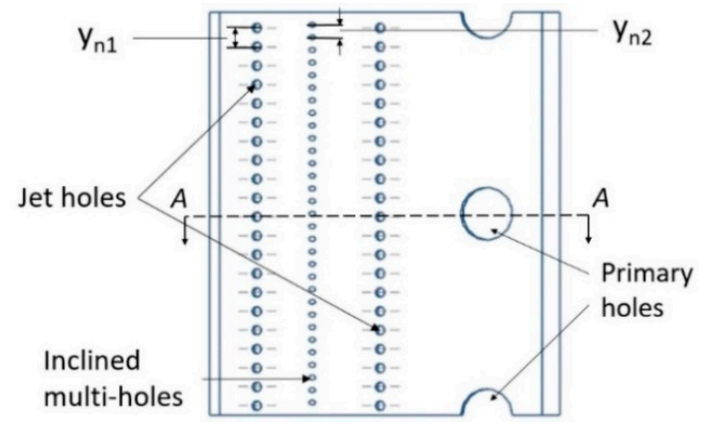

(b)

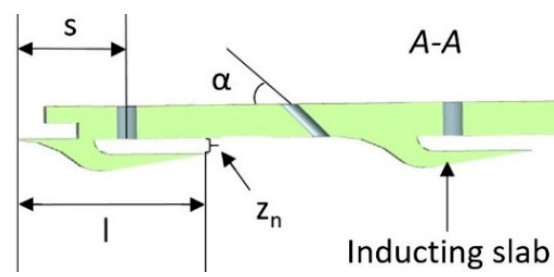

(c)

Figure 10. Scheme $C$ cooling structure layout: (a) cooling scheme of flame tube wall; (b) flame tube wall of primary zone; (c) section A-A.

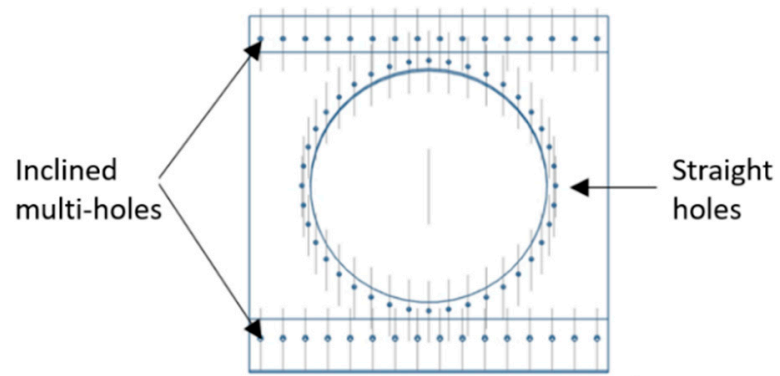

Figure 11. Cooling structure of the flame tube head.

Table 1. Geometric parameter of cooling schemes.

\begin{tabular}{|c|c|c|c|}
\hline Scheme & Cooling Structure & Symbol & Value \\
\hline \multirow{4}{*}{ A } & \multirow{4}{*}{ Inclined multi-hole } & $\mathrm{D}_{\mathrm{m}}(\mathrm{mm})$ & 0.5 \\
\hline & & $x_{n}$ & 8 \\
\hline & & $Y_{n 2}$ & 3 \\
\hline & & $\alpha$ & $30^{\circ}$ \\
\hline \multirow{7}{*}{ B } & \multirow{4}{*}{ Impingement-film } & $\mathrm{D}_{\mathrm{j}}(\mathrm{mm})$ & 1 \\
\hline & & $\mathrm{Y}_{\mathrm{n} 1}$ & 2 \\
\hline & & $Z_{n}$ & 0.5 \\
\hline & & $\mathrm{s} / 1$ & 0.5 \\
\hline & \multirow{3}{*}{ Inclined multi-hole } & $\mathrm{D}_{\mathrm{m}}(\mathrm{mm})$ & 0.8 \\
\hline & & $\mathrm{Y}_{\mathrm{n} 2}$ & 4 \\
\hline & & $\alpha$ & $30^{\circ}$ \\
\hline \multirow{7}{*}{$\mathrm{C}$} & \multirow{4}{*}{ Impingement-film } & $\mathrm{D}_{\mathrm{j}}(\mathrm{mm})$ & 1.6 \\
\hline & & $Y_{n 1}$ & 2 \\
\hline & & $\mathrm{Z}_{\mathrm{n}}$ & 0.5 \\
\hline & & $\mathrm{s} / 1$ & 0.5 \\
\hline & \multirow{3}{*}{ Inclined multi-hole } & $\mathrm{D}_{\mathrm{m}}(\mathrm{mm})$ & 0.8 \\
\hline & & $Y_{n 2}$ & 4 \\
\hline & & $\alpha$ & $30^{\circ}$ \\
\hline
\end{tabular}




\section{Methodology of Experiment and Numerical Simulation}

\subsection{Experiment Methods}

\subsubsection{Experiment System}

The schematic diagram of the experimental setup is depicted in Figure 12. The combustion chamber in the experiment is the unit structure of the real combustor, which is shown in Figure 13. The equivalent ratio of the primary zone of the combustor is $0.9: 1$, referring to the combustor designed by Guoyu Ding [1-3]. The experiments were conducted with a single screw air compressor, the maximum volume flow rate of which is $300 \mathrm{~m}^{3} / \mathrm{h}$ (about $0.07 \mathrm{~kg} / \mathrm{s}$ ). An electric heater with a rated power of $200 \mathrm{KW}$ was employed to heat the air. The volume flow rate of hot gas was measured by a vortex flowmeter. Aviation kerosene was supplied to the nozzle through a pressure gauge, a flowmeter, and a filter. The filtration accuracy of the fuel filter is $10 \mu \mathrm{m}$. A centrifugal nozzle is used with a spray angle of $80^{\circ}$. The inlet temperature and the wall temperature were measured by K-type thermocouples, while the outlet temperature was measured by B-type thermocouples for high temperature. The output signals from the thermocouples were collected by a NI PXIe-1082 data acquisition system.

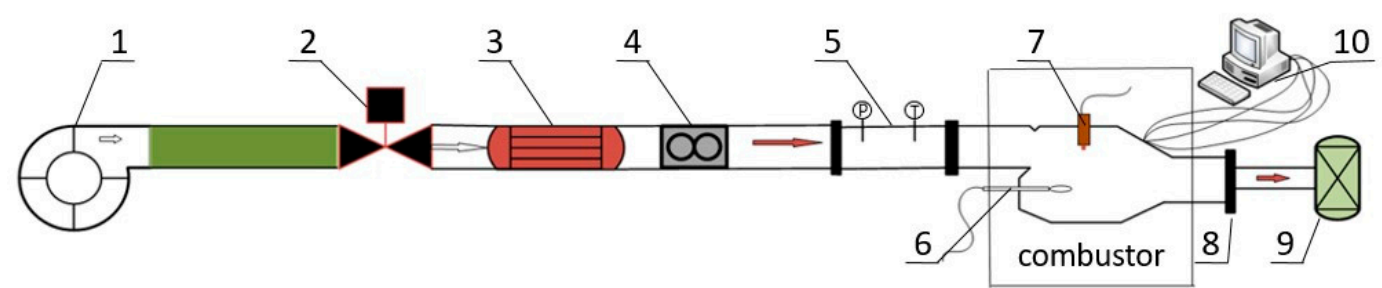

1.single screw air compressor 2.valve 3.electric heater 4.vortex flowmeter 5.inlet measurement section 6.fuel nozzle 7. igniter 8.outlet temperature measurement 9.cooler 10.NI data acquisitions system

Figure 12. Schematic diagram of the experimental setup.

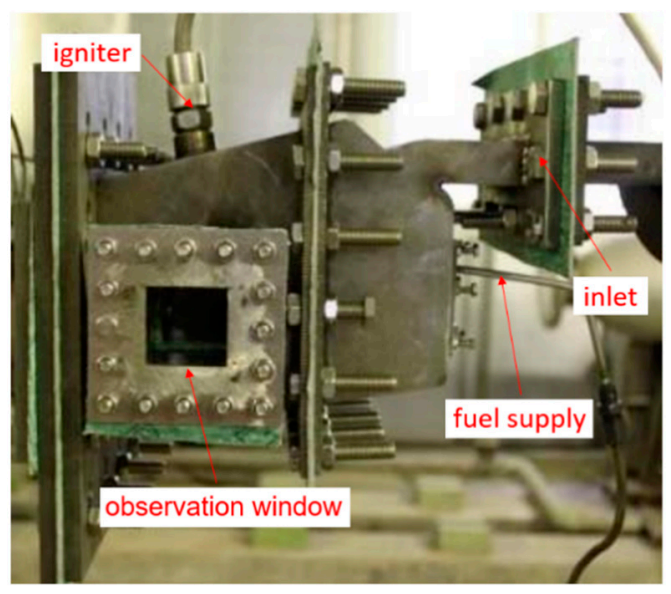

Figure 13. A photograph of the combustor.

The schematic diagram of the temperature measuring points is shown in Figure 14. Two columns of thermocouples are aligned along the streamwise direction. The schematic diagram of outlet temperature measurement points is shown in Figure 15. The outlet temperature $\overline{T_{4}}$ is the average value of all the 12 points. The experimental uncertainties are summarized in Table 2. 


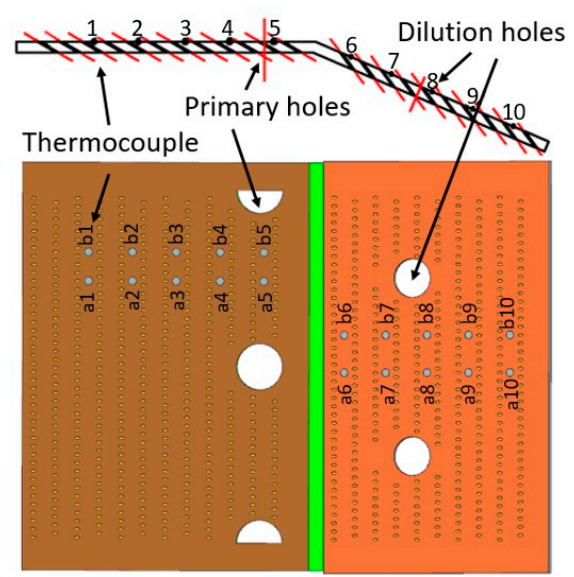

(a)

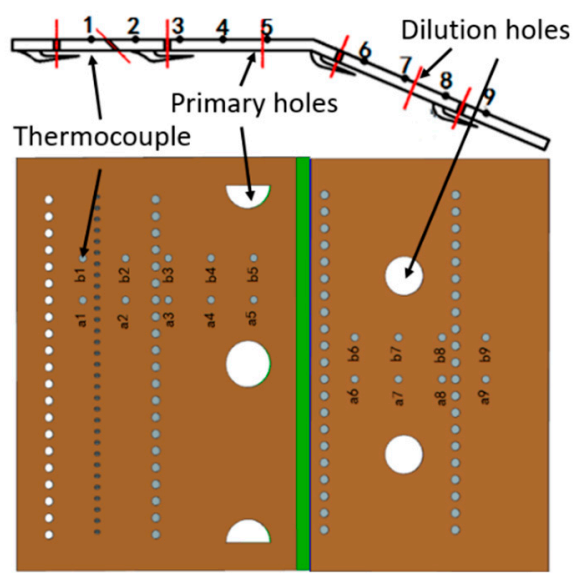

(c)

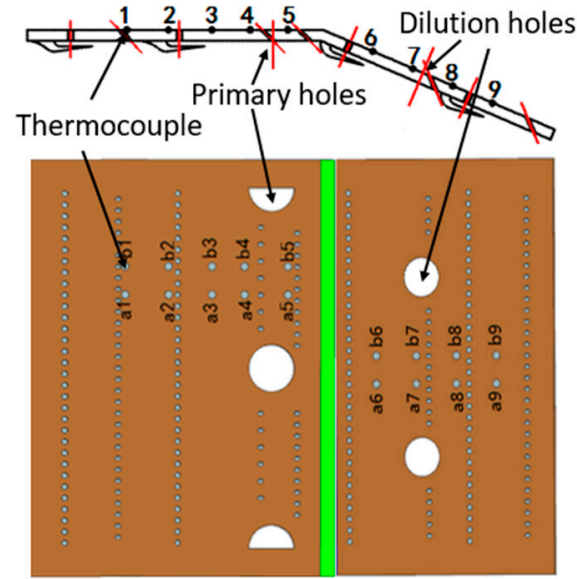

(b)

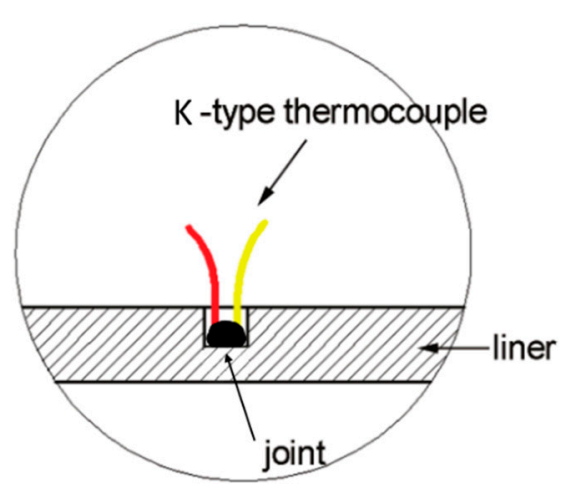

(d)

Figure 14. Schematic of the liner and thermocouple laying: (a) Scheme A; (b) Scheme B; (c) Scheme C; (d) thermocouples on the liner.

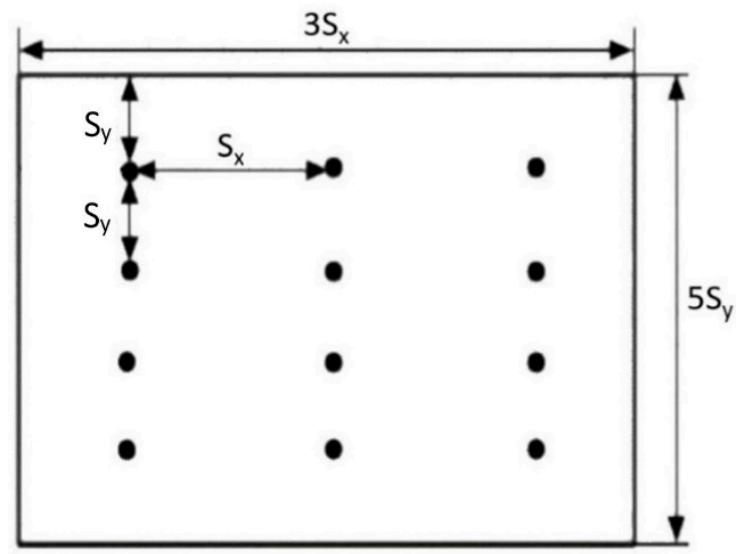

Figure 15. Schematic diagram of B-type thermocouple measuring points on outlet. 
Table 2. Uncertainties of measured parameters.

\begin{tabular}{cccc}
\hline Parameter & $\boldsymbol{T}(\boldsymbol{K})$ & $\boldsymbol{\Delta} \mathbf{T}(\boldsymbol{K})$ & $\boldsymbol{\Delta} \mathbf{T} / \mathbf{T}(\%)$ \\
\hline$\overline{T_{4}}$ & $1144-1512$ & $\pm(2.86-3.78)$ & \pm 0.25 \\
$T_{3}$ & $373-423$ & $\pm(1.87-2.12)$ & \pm 0.5 \\
$T_{w}$ & $392-562$ & $\pm(1.96-2.81)$ & \pm 0.5 \\
\hline
\end{tabular}

\subsubsection{Test Conditions}

The test conditions are shown in Table 3. The range of the Mach number of the combustor inlet is $0.12 \sim 0.18$. The range of fuel-air ratio (FAR) is $0.02-0.03$. The range of the inlet temperature $\mathrm{T}_{3}$ is $373-423 \mathrm{~K}$. The inlet Mach numbers of the no.1 and the no.4 experimental condition are different due to the difference in the inlet temperature. The no.1 experimental condition shares the same inlet velocity with the no.4 experimental condition.

Table 3. Test conditions.

\begin{tabular}{ccccc}
\hline No. & $\mathbf{T}_{\mathbf{3}} \mathbf{( K )}$ & $\mathbf{V}(\mathbf{m} / \mathbf{s})$ & $\mathbf{M a}$ & $\mathbf{F A R}$ \\
\hline 1 & 373 & 70 & 0.18 & 0.03 \\
2 & 423 & 50 & 0.12 & 0.03 \\
3 & 423 & 70 & 0.17 & 0.02 \\
4 & 423 & 70 & 0.17 & 0.03 \\
\hline
\end{tabular}

\subsubsection{Parameter Definitions}

The wall temperature along the streamwise direction, $T_{i}$, is defined as the average value of temperature measured at two points a and b (see Figure 14):

$$
T_{i}=\frac{T_{a i}+T_{b i}}{2},
$$

where $i$ is the $i$ th measuring point.

\subsection{Numerical Simulation Methods}

\subsubsection{Meshing}

The grid of the calculation model is shown in Figure 16. The structured grid is adopted in the head of the flame tube, the primary zone, and the dilution zone. While the unstructured tetrahedral grid is used in the triple-swirler and the surrounding fluid domain due to the complexity of the structure. The wall temperature of the flame tube is related to combustion, while the flow field has a great influence on combustion. Therefore, the flow field structure is used to verify the grid independence. Figure 17 shows the zero-velocity line of the calculation model calculated under different grid numbers and the grid with about 5.6 million cells is selected. The range of $y+$ is controlled between 20-60, which is shown in Table 4.

\subsubsection{Calculation Methods and Boundary Conditions}

The three-dimensional simulations were performed using the commercial CFD (Computational Fluid Dynamics) software package FLUENT. The standard k- $\varepsilon$ model with the standard wall function is selected for the turbulence model.

$$
\begin{gathered}
\frac{\partial(\rho k)}{\partial t}+\frac{\partial\left(\rho k u_{i}\right)}{\partial x_{i}}=\frac{\partial}{\partial x_{j}}\left[\left(\mu+\frac{\mu_{t}}{\sigma_{k}}\right) \frac{\partial k}{\partial x_{j}}\right]+G_{k}+G_{b}-\rho \varepsilon-Y_{M}+S_{k}, \\
\frac{\partial(\rho \varepsilon)}{\partial t}+\frac{\partial\left(\rho \varepsilon u_{i}\right)}{\partial x_{i}}=\frac{\partial}{\partial x_{j}}\left[\left(\mu+\frac{\mu_{t}}{\sigma_{\varepsilon}}\right) \frac{\partial \varepsilon}{\partial x_{j}}\right]+C_{1 \varepsilon} \frac{\varepsilon}{k}\left(G_{k}+C_{3 \varepsilon} G_{b}\right)-C_{2 \varepsilon} \rho \frac{\varepsilon^{2}}{k}+S_{\varepsilon},
\end{gathered}
$$


where $G_{k}$ represents the generation of turbulence kinetic energy due to the mean velocity gradients, $G_{b}$ is the generation of turbulence kinetic energy due to buoyancy, $Y_{M}$ represents the contribution of the fluctuating dilatation in compressible turbulence to the overall dissipation rate, $C_{1 \varepsilon}, C_{2 \varepsilon}$, and $C_{3 \varepsilon}$ are constants. $\sigma_{k}$ and $\sigma_{\varepsilon}$ are the turbulent Prandtl numbers for $k$ and $\varepsilon$, respectively. $S_{k}$ and $S_{\varepsilon}$ are user-defined source terms.

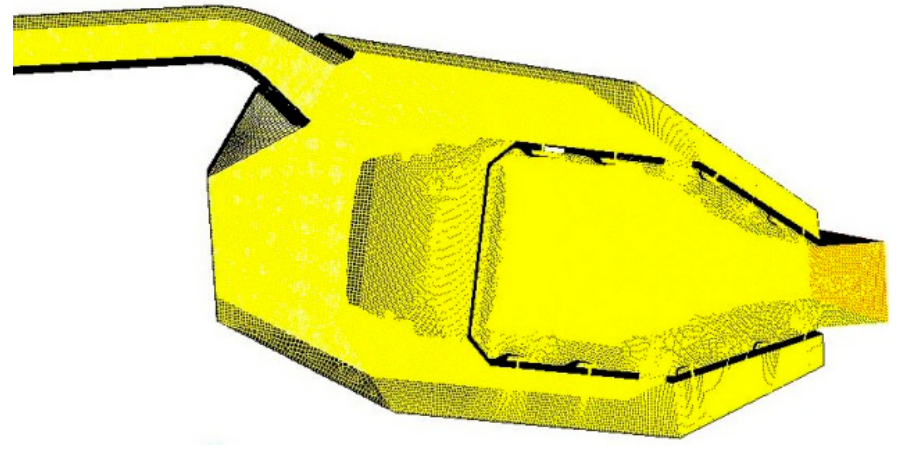

(a)

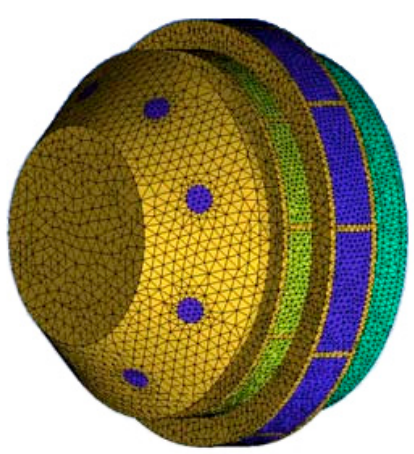

(b)

Figure 16. Computational grid: (a) overall meshing of the combustor (b) details of swirler.

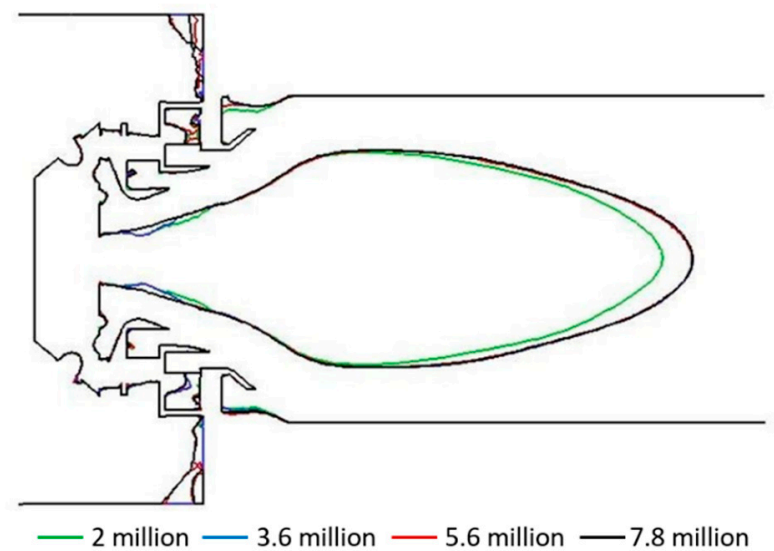

Figure 17. Grid independence test.

Table 4. $\mathrm{Y}+$ value in computational grid.

\begin{tabular}{cc}
\hline Position & Range of Y+ Value \\
\hline Flame tube wall & $30-50$ \\
Triple-swirler & $20-60$ \\
Primary hole & $20-40$ \\
Dilution hole & $20-40$ \\
\hline
\end{tabular}

The numerical simulation of turbulent combustion is performed by applying the probabilitydensity-function models (PDF) to non-premixed flames. As there are fuel particles inside the combustion chamber, the P1 radiation model is employed, and the wall emissivity is set to 0.8 . The discrete phase model is adopted to simulate the gas-liquid two-phase flow. FLUENT predicts the trajectory of a discrete phase particle by integrating the force balance on the particle, which is written in a Lagrangian reference frame. This force balance equates the particle inertia with the forces acting on the particle, and can be written as

$$
\frac{d \vec{u}_{p}}{d t}=\frac{\vec{u}-\vec{u}_{p}}{\tau_{r}}+\frac{\vec{g}\left(\rho_{p}-\rho\right)}{\rho_{p}}+\vec{F}
$$


where $\vec{F}$ is an additional acceleration (force/unit particle mass) term, $\tau_{r}$ is the droplet or particle relaxation time, $\vec{u}$ is the fluid phase velocity, $\vec{u}_{p}$ is the particle velocity, $\rho$ is the fluid density and $\rho_{p}$ is the density of the particle.

Incompressible ideal gas is used as the working fluid. The inlet boundary condition is defined as velocity inlet, while the outlet boundary condition is defined as pressure outlet. As the real combustion chamber is a multi-head annular combustor, two lateral planes are periodic and non-slip condition is employed along all other walls. The three schemes share the same coolant mass flow rate per unit area (MPA), and the overall coolant flow rate does not exceed $25 \%$ of the total flow of the combustor. The other boundary conditions are listed in Table 5.

Table 5. Boundary conditions (numerical simulation).

\begin{tabular}{cccc}
\hline Inlet Velocity & Inlet Temperature & Outlet Pressure & FAR \\
\hline $70 \mathrm{~m} / \mathrm{s}$ & $423 \mathrm{~K}$ & $1 \mathrm{~atm}$ & 0.03 \\
\hline
\end{tabular}

\subsubsection{Validations}

As shown in Figure 18, the direction along the wall surface of the flame tube is chosen as the $\mathrm{x}$ axis direction. The center line of the primary holes is located at $x=43 \mathrm{~mm}$, and that of the dilution holes is located at $x=74 \mathrm{~mm}$. In Scheme $C$, the numerical results are compared with that of the experimental results (see Figure 19). The curve of the numerical simulation results almost coincides with that of the experimental data in the primary zone, while the wall temperature of simulation is higher in the dilution zone. The maximum error between the numerical simulation and the experiments does not exceed $13 \%$.

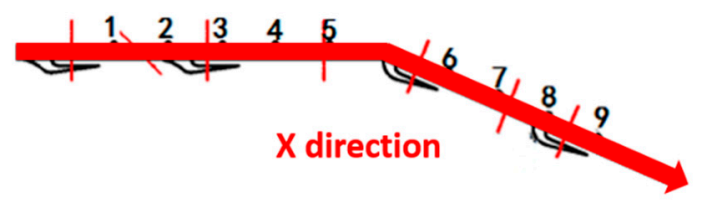

Figure 18. Schematic diagram of $x$ axis direction.

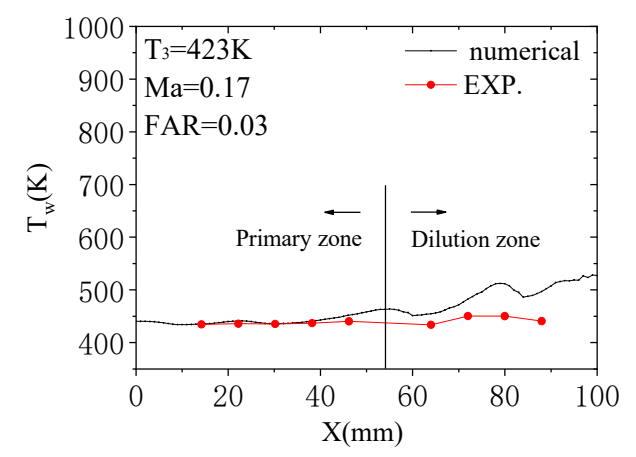

Figure 19. Comparison of the numerical simulation and experimental data.

\section{Results and Discussion}

\subsection{Scheme A Result Analysis}

The experimental wall temperatures in Scheme A are shown in Figure 20. Measuring point one is downstream of the third row of multi-inclined holes and directly facing the combustion core area, resulting in a high wall temperature of the flame tube. With the growth of film formed by the outflow from multi-inclined holes, the wall temperature of the subsequent area declines. The outflow 
of primary holes and dilution holes would cause damage to the near-wall flow field, which leads to an increase in the turbulence of the wall-attached airflow. Thus, the wall temperature is significantly increased due to the damage to the film. Then, the wall temperature decreases gradually due to the coverage of the film after the dilution holes.

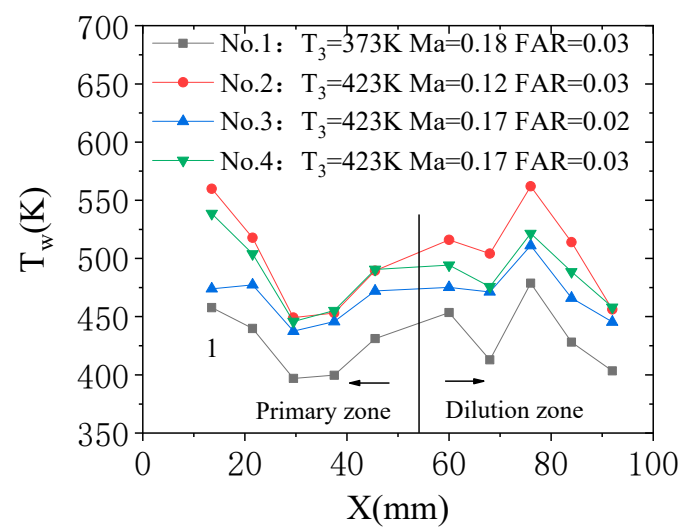

Figure 20. Wall temperature in Scheme A (experimental data).

The wall temperature of the flame tube increases with the inlet temperature. The increase in the inlet Mach number leads to an increase in the amount of cooling air. Therefore, the cooling effect has been improved in the first few rows of multi-inclined holes, and the wall temperature is also decreased to a certain extent in the dilution zone. Comparing the no.3 and the no.4 experimental conditions, the wall temperature of the flame tube is, on the whole, slightly increased with the FAR.

\subsection{Scheme B Result Analysis}

The wall temperature distribution in Scheme B is shown in Figure 21. The wall temperature of measuring point one and two are relatively low due to the protection of the upstream airflow from multi-inclined holes (see Figure 14). Measuring point three has a low temperature as a consequence of the effect of impingement-film cooling. A high wall temperature of the flame tube is observed at measuring point four since the location directly faces the combustion core area and is far away from the jet holes. The wall temperature shows a slightly upward trend in the dilution zone because of the decrease in the cooling air along the way.

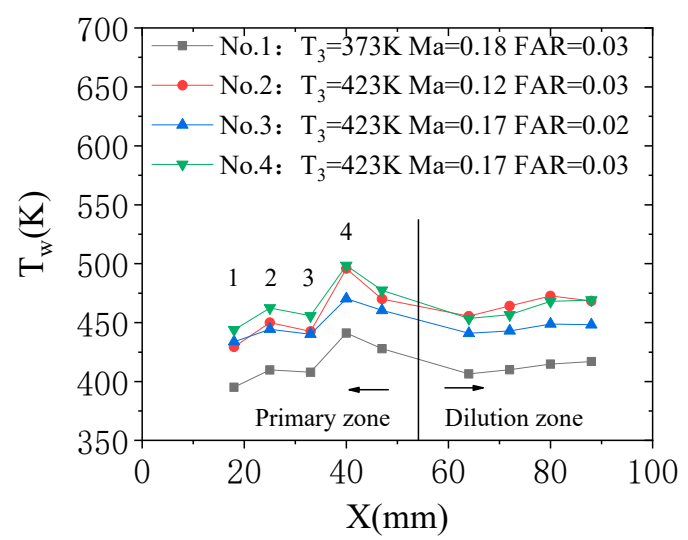

Figure 21. Wall temperature in Scheme B (experimental data).

Comparing all the test conditions, some conclusions are summarized as following. The temperature of the flame wall increases with the inlet temperature by $50 \mathrm{~K}$ on average. The actual fuel supply increases with the inlet Mach number and the wall temperature increases to a certain extent in the 
primary zone. The wall temperature of the flame tube is increased by about $17 \mathrm{~K}$ on average with the increase in the FAR.

\subsection{Scheme C Result Analysis}

\subsubsection{Outlet Temperature}

Since the cooling structure in this study has little impact on combustion performance, the outlet temperatures of each test condition in Scheme $C$ are listed to represent the performance of the combustion chamber, as shown in Table 6. With the increase in inlet temperature, inlet Mach number, and FAR, the outlet temperature of the combustion chamber shows an upward trend. The minimum temperature rise of the combustor is $721 \mathrm{~K}$ and the maximum is $1089 \mathrm{~K}$ in the parameter range.

Table 6. Outlet temperature (experimental data).

\begin{tabular}{cccccc}
\hline No. & $\boldsymbol{T}_{3}(\mathbf{K})$ & Ma & FAR & $\overline{\boldsymbol{T}_{4}}(\boldsymbol{K})$ & $\boldsymbol{\Delta} \boldsymbol{T}(\boldsymbol{K})$ \\
\hline 1 & 373 & 0.18 & 0.03 & 1329 & 956 \\
2 & 423 & 0.12 & 0.03 & 1330 & 907 \\
3 & 423 & 0.17 & 0.02 & 1144 & 721 \\
4 & 423 & 0.17 & 0.03 & 1512 & 1089 \\
\hline
\end{tabular}

\subsubsection{Wall Temperature Analysis}

The experimental wall temperature distribution and the numerical simulation results are shown in Figures 22 and 23, respectively. The wall temperature in the primary zone is lower than that in the dilution zone and the temperature distribution is more uniform. Due to the combined effect of the cooling air and the outflow from the outer swirler, the wall temperature does not exceed $500 \mathrm{~K}$ in the primary zone. In the dilution zone, due to the lack of the protection from the upstream coolant, hot spots exist and the local temperature exceeds $580 \mathrm{~K}$. As a consequence, the overall cooling effect of the combustor can be improved by increasing the proportion of coolant air in the dilution zone properly.

The wall temperature shows an upward trend with the increase in the inlet temperature. On the one hand, the quality of coolant air decreases when the inlet temperature increases. On the other hand, the vaporization and atomization effect of kerosene is enhanced, and the chemical reaction is accelerated, which leads to an increase in the combustion efficiency. The actual fuel supply and the fuel heat release are increased due to the increase in the inlet Mach number, which leads to a certain increase in the temperature in the primary zone. Comparing the no. 3 and the no.4 experimental conditions, $i$ can be concluded that the FAR has little effect on the wall temperature.

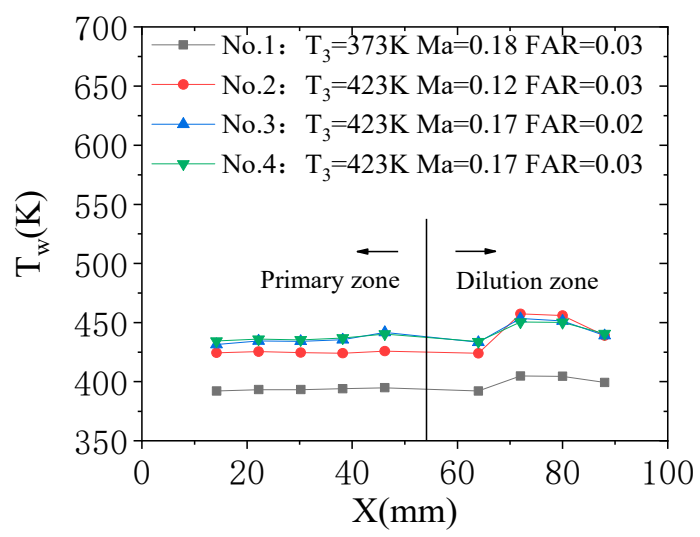

Figure 22. Wall temperature in Scheme C (experimental data). 


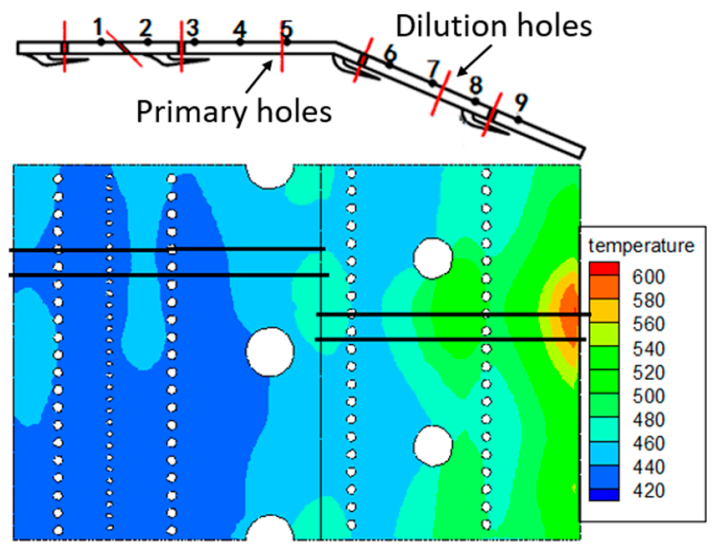

Figure 23. Numerical simulation of wall temperature distribution, $\mathrm{K}$ (no.4: $\mathrm{T}_{3}=423 \mathrm{~K} \mathrm{Ma}=0.17$ fuel-air ratio $(\mathrm{FAR})=0.03)$.

\subsection{Analysis of Cooling Schemes}

The comparative graphs of three schemes under different experimental conditions are shown in Figure 24. The lowest wall temperature and the best cooling effect are observed in Scheme C. The highest wall temperature is observed in Scheme A. The result in Scheme B is between them. The wall temperature distribution in Scheme $\mathrm{C}$ is more uniform than that in Scheme $\mathrm{A}$ and $\mathrm{B}$. The experiment conducted on the impingement-film and inclined multi-hole structure shows a better cooling effect than that conducted on the inclined multi-hole structure. Compared with the row number of multi-inclined holes, the diameter of jet hole has a more significant influence on the cooling effect.

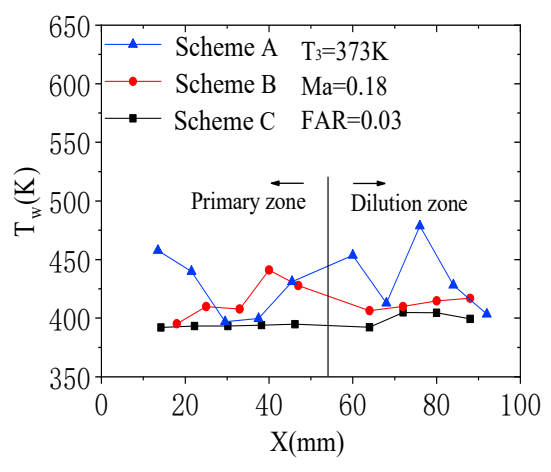

(a)

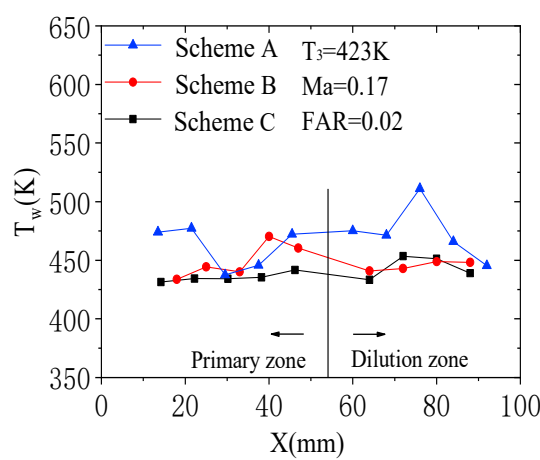

(c)

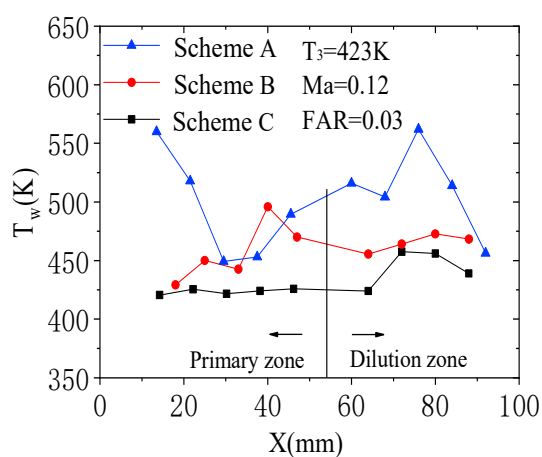

(b)

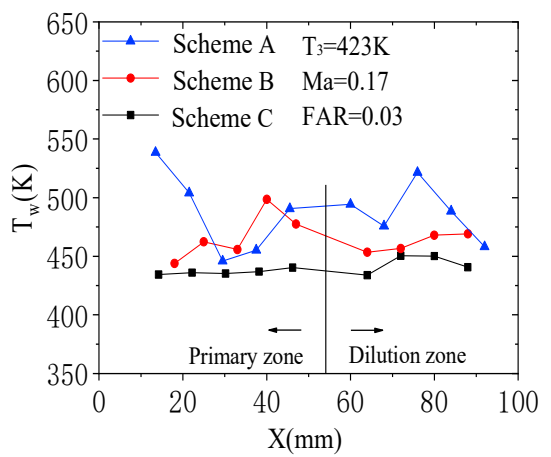

(d)

Figure 24. Comparison of wall temperatures in different structures (experimental data): (a) no.1: $T_{3}=373 \mathrm{~K} \mathrm{Ma}=0.18 \mathrm{FAR}=0.03 ;(\mathbf{b})$ no.2: $T_{3}=423 \mathrm{~K} \mathrm{Ma}=0.12 \mathrm{FAR}=0.03 ;(\mathbf{c})$ no. $3: T_{3}=423 \mathrm{~K}$ $\mathrm{Ma}=0.17 \mathrm{FAR}=0.02 ;(\mathbf{d})$ no. $4: T_{3}=423 \mathrm{~K} \mathrm{Ma}=0.17 \mathrm{FAR}=0.03$. 


\subsection{Numerical Simulation Analysis in Scheme $C$}

\subsubsection{Flow Field and Temperature Field}

In order to further analyze the flow field and wall temperature characteristics of Scheme C, a numerical simulation study was carried out. The flow field distribution at the given cross section, which is through a primary hole, is shown in Figure 25. With the co-influence of the airflow from primary holes, inner swirler and intermediate swirler, the penetration depth of primary holes reaches half the height of the flame tube, which promote the formation of the recirculation zone.

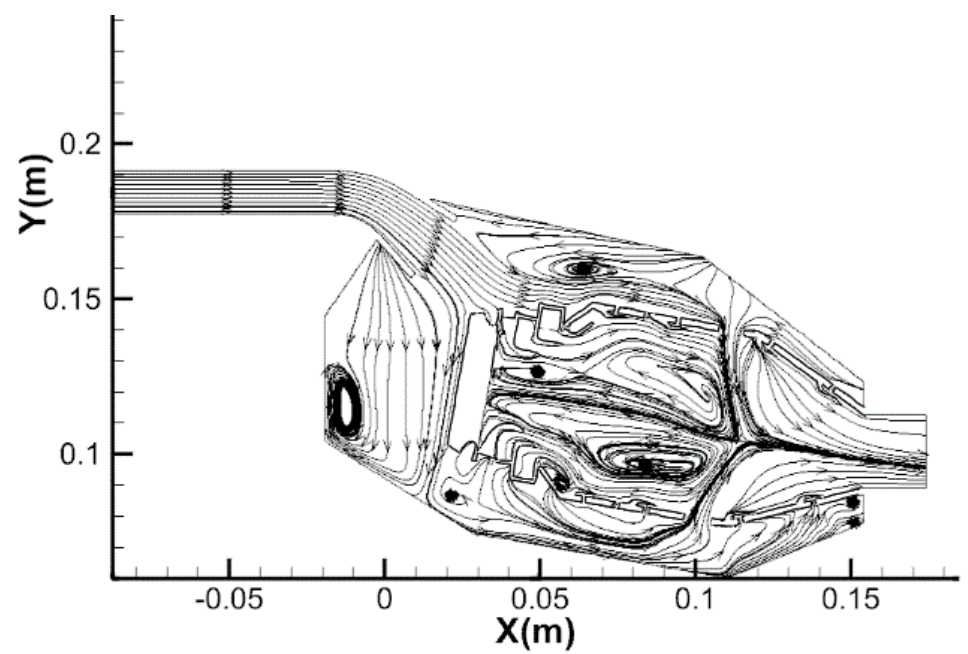

Figure 25. Flow field distribution (numerical simulation).

The temperature distribution at the given cross section is shown in Figure 26. The high-temperature area is mainly concentrated in the primary zone. While the temperature is significantly reduced in the dilution zone due to the effect of the dilution airflow.

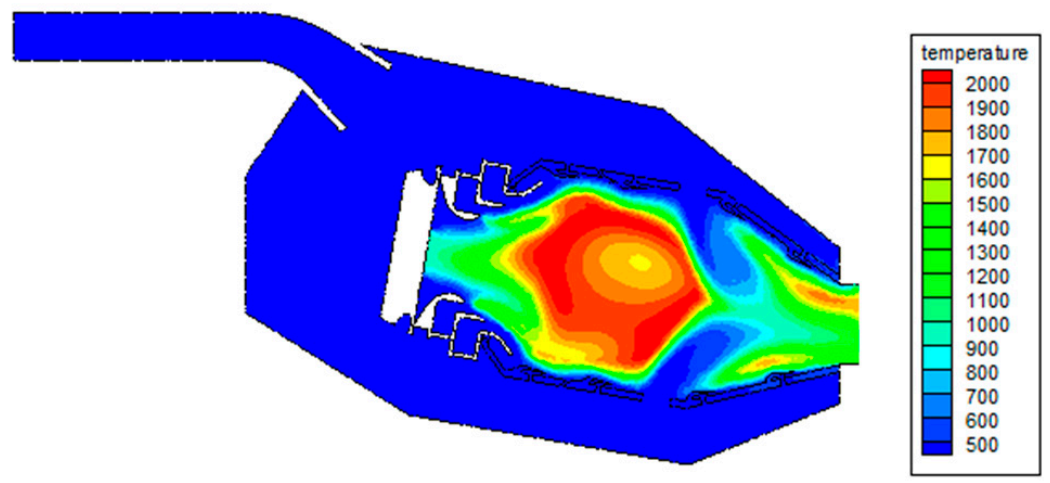

Figure 26. Temperature distribution (numerical simulation, K).

\subsubsection{Near-Wall Flow Field Analysis}

The near-wall flow field of the flame tube is shown in Figure 27. The airflow of the outer swirler is close to the wall and protects the first inducting slab. The airflow of jet holes flows out from the slit outlet and stays attached to the wall surface, which can effectively protect the flame tube. The cooling air from the multi-inclined holes flows close to the second inducting slab, which isolates hot gas and the flame tube and avoids the excessively high temperature of the inducting slab. A good wall-attached effect is observed in the dilution zone, which is beneficial for the cooling effect. 


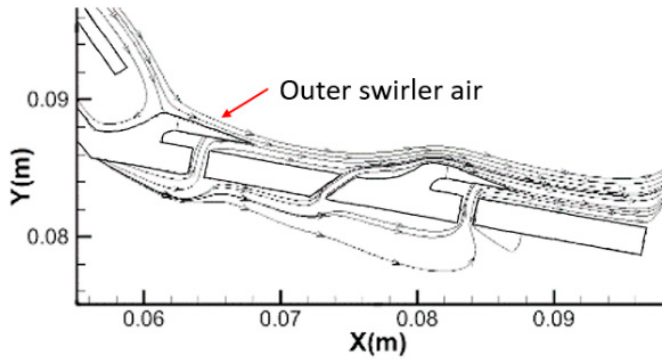

(a)

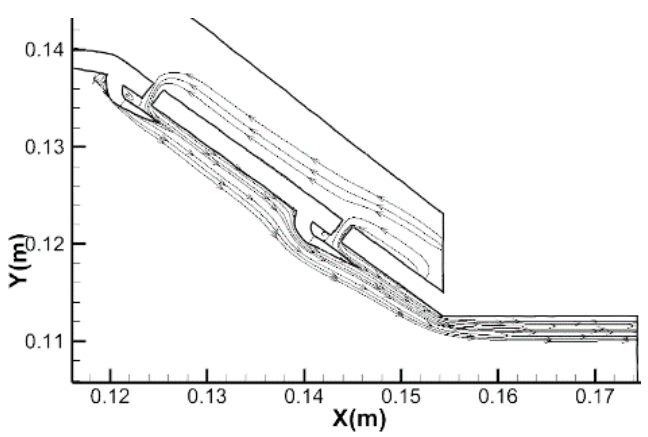

(c)

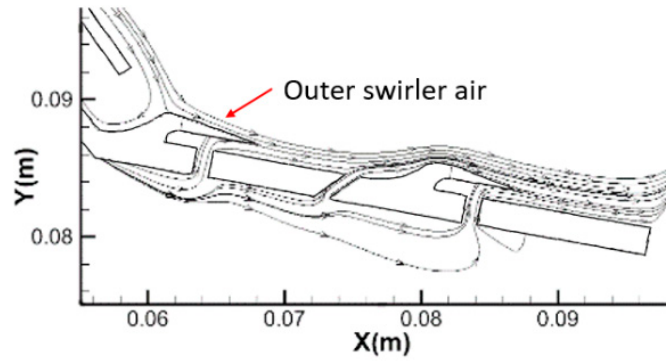

(b)

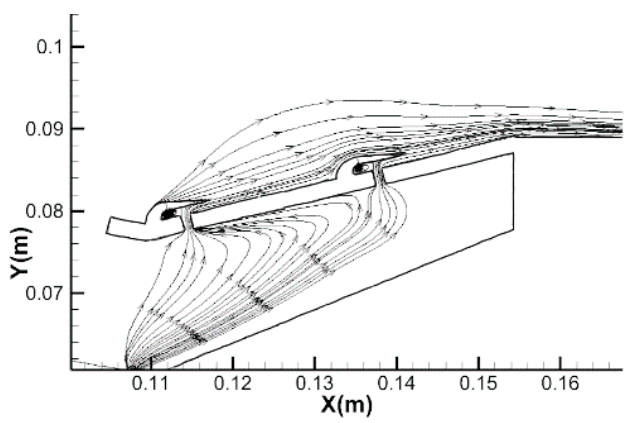

(d)

Figure 27. Near-wall flow field of the flame tube (numerical simulation): (a) primary zone near outer ring; (b) primary zone near inner ring; (c) dilution zone near outer ring; (d) dilution zone near inner ring.

\section{Conclusions}

In this paper, a composite cooling structure (Scheme B, C) with impingement-film and multi-inclined holes is proposed, which shows a better cooling effect than the traditional effusion cooling structure. The cooling study of the flame tube in a small triple-swirler combustor is carried out. The main conclusions are as follows:

- The lowest wall temperature and the best cooling effect are observed in Scheme $C$. The experiment conducted on the impingement-film and inclined multi-hole structure shows a better cooling effect than that conducted on the traditional inclined multi-hole structure;

- The airflow of the outer swirler is close to the wall and protects the first inducting slab. The cooling air from multi-inclined holes flows close to the second inducting slab, which isolates hot gas and the flame tube and avoids the excessively high temperature of the inducting slab;

- The overall cooling effect of the combustor in Scheme $C$ can be improved by increasing the proportion of coolant air in the dilution zone properly. Compared with the rows of multi-inclined holes, the diameter of the jet hole has a more significant influence on the cooling effect.

Previous studies have mainly focused on the unit structural model, such as inclined multi-hole structure and impingement-film cooling structure. However, the effect of film cooling under turbulent combustion conditions in a multi-swirler combustor is rarely studied. At present, the effusion cooling structure is employed in most advanced combustion chambers, such as the GE90 turbofan engine [21]. However, the advantages of the inclined multi-hole structure are not obvious due to the structural characteristics of the small triple-swirler combustor. The cooling effect of the impingement-film and inclined multi-hole cooling structure is better than that of the traditional inclined multi-hole structure under different experimental conditions. It is expected that the present work may provide a new idea for the cooling structure design of a multi-swirler combustor. 
Author Contributions: J.Z. constructed the experimental idea, theoretical analysis, and experimental simulation, and wrote this paper; Y.S. formulated research objectives, analyzed the experimental results, provided theoretical guidance and suggestions and improved the paper; J.L. and X.H. participated in the discussion of the experimental plan and experimental results. All authors have read and agreed to the published version of the manuscript.

Funding: This work was supported by the National Science and Technology Major Project [2017-Ill-0008-0034].

Conflicts of Interest: The authors declare no conflict of interest.

\section{Nomenclature}

$\alpha \quad$ injection angle, ${ }^{\circ}$

$\mathrm{D}_{\mathrm{m}} \quad$ diameter of multi-inclined hole, $\mathrm{mm}$

$\mathrm{D}_{\mathrm{j}} \quad$ diameter of jet hole, $\mathrm{mm}$

Ma Mach number

$\mathrm{s} / \mathrm{l}$ location ratio of jet hole

$T_{3} \quad$ inlet temperature, $\mathrm{K}$

$\overline{T_{4}} \quad$ outlet temperature, $\mathrm{K}$

$\mathrm{T}_{\mathrm{c}} \quad$ cooling air temperature, $\mathrm{K}$

$\mathrm{T}_{\mathrm{h}} \quad$ hot air temperature, $\mathrm{K}$

$T_{w} \quad$ wall temperature, $\mathrm{K}$

$X_{n} \quad$ non-dimensional streamwise spacing, $x_{n} / D_{m}$

$Y_{n 1} \quad$ non-dimensional spanwise spacing, $y_{n 1} / D_{j}$

$Y_{n 2}$ non-dimensional spanwise spacing, $y_{n 2} / D_{m}$

$\mathrm{Z}_{\mathrm{n}} \quad$ non-dimensional jet-to-plate pitch, $\mathrm{z}_{\mathrm{n}} / \mathrm{D}_{\mathrm{j}}$

$\Delta T \quad$ temperature rise, $\mathrm{K}$

\section{References}

1. Guoyu, D.; Xiaomin, H.; Ziqiang, Z.; Bokun, A.; Yaoyu, S.; Yixiao, Z. Effect of dilution holes on the performance of a triple swirler combustor. Chin. J. Aeronaut. 2014, 27, 1421-1429. [CrossRef]

2. Ding, G.; He, X.; Zhao, Z.; Jin, Y.; Zhu, Z. Effect of different triple swirlers on the performance of a triple swirler combustor. Proc. Inst. Mech. Eng. Part G J. Aerosp. Eng. 2015, 229, 26-37. [CrossRef]

3. Ding, G.; He, X.; Xue, C.; Zhao, Z.; Jin, Y. Preliminary design and experimental verification of a triple swirler combustor. Proc. Inst. Mech. Eng. Part G J. Aerosp. Eng. 2015, 229, 2258-2271. [CrossRef]

4. Zhao, Z.; He, X.; Ding, G.; Li, M.; Jiang, P.; Huanga, W. Effect of rotational direction of triple-swirler on cold flow characteristics of a model combustor. Proc. Inst. Mech. Eng. Part G J. Aerosp. Eng. 2017, 231, 918-930. [CrossRef]

5. Foust, M.J.; Thomsen, D.; Stickles, R.; Cooper, C.; Dodds, W. Development of the GE aviation low emissions TAPS combustor for next generation aircraft engines. In Proceedings of the 50th AIAA Aerospace Sciences Meeting Including the New Horizons Forum and Aerospace Exposition, Nashville, TN, USA, 9-12 January 2012.

6. Ding, G.Y.; He, X.M.; Zhu, Y.X.; Jiang, P.; Jin, Y. Effects of rotating direction combination on performance of a small-scale triple swirler combustor. Tuijin Jishu/J. Propuls. Technol. 2016, 37, 2097-2106. [CrossRef]

7. Ding, G.Y.; He, X.M.; Xue, C.; Hong, L. Experiment on effect of dome and dilution holes on outlet temperature distribution for triple swirler combustor. Hangkong Dongli Xuebao/J. Aerosp. Power 2015, 30, 807-813. [CrossRef]

8. Song, K.; Zhang, J.Y.; Wang, J.X.; Liu, M.; He, X.M. Experimental Study on Overall Cooling Effectiveness of Inclined Multihole under the Same Pressure Differential. Tuijin Jishu/J. Propuls. Technol. 2019, 40. [CrossRef]

9. Ballal, D.R.; Lefebvre, A.H. Proposed Method for Calculating Film-Cooled Wall Temperatures in Gas Turbine Combustion Chambers; Cranfield Institute of Technology: Bedford, UK, 1972; Proceedings of the ASME Pap.

10. Bernhard Gustafsson, K.M.; Gunnar Johansson, T. An experimental study of surface temperature distribution on effusion-cooled plates. J. Eng. Gas Turbines Power 2001, 123, 308-316. [CrossRef]

11. Andrews, G.E.; Asere, A.A.; Gupta, M.L.; Mkpadi, M.C. Full coverage discrete hole film cooling: The influence of hole size. In Proceedings of the ASME 1985 International Gas Turbine Conference and Exhibit, Houston, TX, USA, 18-21 March 1985; American Society of Mechanical Engineers (Paper). ASME: New York, NY, USA. 
12. Andrews, G.E.; Gupta, M.L.; Mkpadi, M.C. Full Coverage Discrete Hole Film Cooling: Cooling Effectiveness. Int. J. Turbo Jet Engines 1985, 2, 199-212. [CrossRef]

13. Andrews, G.E.; Alikhanizadeh, M.; Tehrani, F.B.; Hussain, C.I.; Azari, M.S.K. Small Diameter Film Cooling Holes: The Influence of Hole Size and Pitch. Int. J. Turbo Jet Engines 1988, 5, 61-72. [CrossRef]

14. Andrews, G.E.; Asere, A.A.; Gupta, M.L.; Mkpadi, M.C.; Tirmahi, A. Full coverage discrete hole film cooling. The influence of the number of holes and pressure loss. In Proceedings of the ASME 1990 International Gas Turbine and Aeroengine Congress and Exposition, Brussels, Belgium, 11-14 June 1990; American Society of Mechanical Engineers (Paper). ASME: New York, NY, USA.

15. Andrews, G.E.; Khalifa, I.M.; Asere, A.A.; Bazdidi-Tehrani, F. Full coverage effusion film cooling with inclined holes. In Proceedings of the ASME Turbo Expo; American Society of Mechanical Engineers (ASME), Houston, TX, USA, 5-8 June 1995; Volume 4.

16. Zhang, J.; Yuan, C.; Ji, P.; Wei, J.; He, X. Experimental investigation on the overall cooling effectiveness of t-type impinging-film cooling. Appl. Therm. Eng. 2018, 128, 595-603. [CrossRef]

17. Wei, J.; Zhang, J.; Li, S.; Wang, F. Numerical study on impinging-film hybrid cooling effect with different geometries. Int. J. Therm. Sci. 2015, 92, 199-216. [CrossRef]

18. Zhang, J.; Wei, J.; Wang, F.; Jin, Y.; He, X. Experimental and numerical investigation of the effectiveness of impingement-film hybrid cooling. Heat Transf. Res. 2019, 50, 1333-1350. [CrossRef]

19. Jambunathan, K.; Lai, E.; Moss, M.A.; Button, B.L. A review of heat transfer data for single circular jet impingement. Int. J. Heat Fluid Flow 1992, 13, 106-115. [CrossRef]

20. Mongia, H.C. Engineering aspects of complex gas turbine combustion mixers part I: High Delta-T. In Proceedings of the 49th AIAA Aerospace Sciences Meeting including the New Horizons Forum and Aerospace Exposition, Orlando, FL, USA, 4-7 January 2011; pp. 1-16. [CrossRef]

21. Viars, P. The Impact of IHPTET on the Engine/Aircraft System. In Proceedings of the Aircraft Design and Operations Meeting, Seattle, WA, USA, 31 July-2 August 1989; AIAA: Reston, VA, USA.

Publisher's Note: MDPI stays neutral with regard to jurisdictional claims in published maps and institutional affiliations.

(C) 2020 by the authors. Licensee MDPI, Basel, Switzerland. This article is an open access article distributed under the terms and conditions of the Creative Commons Attribution (CC BY) license (http://creativecommons.org/licenses/by/4.0/). 